\begin{abstract}
Iranica
Abstracta Iranica Revue bibliographique pour le domaine irano-aryen

Volume 42-43 | 2021

Comptes rendus des publications de 2019-2020

\section{Jeffrey Kotyk. "Indo-Iranian and Islamicate Sources of Astrological Medicine in Medieval China"}

\title{
Alessia Zubani
}

\section{(2) OpenEdition}

1 Journals

\section{Édition électronique}

URL : https://journals.openedition.org/abstractairanica/54319

DOI : 10.4000/abstractairanica.54319

ISSN : 1961-960X

Éditeur :

CNRS (UMR 7528 Mondes iraniens et indiens), Éditions de l'IFRI

\section{Référence électronique}

Alessia Zubani, « Jeffrey Kotyk. "Indo-Iranian and Islamicate Sources of Astrological Medicine in Medieval China" », Abstracta Iranica [En ligne], Volume 42-43 | 2021, document 5, mis en ligne le 30 décembre 2021, consulté le 13 décembre 2022. URL : http://journals.openedition.org/ abstractairanica/54319; DOI : https://doi.org/10.4000/abstractairanica.54319

Ce document a été généré automatiquement le 13 décembre 2022.

Tous droits réservés 


\title{
Jeffrey Kotyk. "Indo-Iranian and Islamicate Sources of Astrological Medicine in Medieval China"
}

\author{
Alessia Zubani
}

\section{RÉFÉRENCE}

Jeffrey Kotyk. "Indo-Iranian and Islamicate Sources of Astrological Medicine in Medieval China", Asia Medicine 14, 2019, p. 30-55.

1 Cette étude explore la question de l'introduction et développement de la médecine astrologique étrangère dans le monde chinois, entre le VIII ${ }^{\mathrm{e}}$ et le XVI ${ }^{\mathrm{e}}$ siècle. L'A. montre l'assimilation dans la Chine médiévale des connaissances et pratiques dérivées par des sources hellénistiques, indiennes, iraniennes et islamiques dans les activités astrologiques censées prédire la maladie. Il se penche également sur la question de l'influence astrale négative, en soulignant que les taoïstes et les bouddhistes avaient adopté des techniques astrologiques étrangères pour dissiper les influences planétaires néfastes, provoquant les maladies (c.-à-d., restrictions alimentaires, étouffements d'encens spécifiques pour chaque planète).

\section{AUTEURS}

ALESSIA ZUBANI

Labex HaStec, EPHE-PSL 